\title{
Prevalências de excesso de peso e de adiposidade excessiva em crianças brasileiras de escolas municipais
}

\author{
Naruna Pereira Rocha, Ana Paula Pereira Castro, Fernanda Martins de Albuquerque, Mariana de
} Santis Filgueiras, Luana Cupertino Milagres, Juliana Farias de Novaes

\begin{abstract}
Resumo
As prevalências de excesso de peso são cada vez maiores na população infantil. A obesidade precoce em crianças pode induzir a alterações do metabolismo paralelamente a elevação do sistema oxidativo e inflamatório conduzindo a complicações cardiometabólicas a curto e em longo prazo. A detecção precoce de alterações da composição corporal em crianças pode auxiliar na modificação do estilo de vida e evitar o desenvolvimento e progressão de comorbidades associadas. Comparar as prevalências de excesso de peso e de adiposidade excessiva em crianças brasileiras matriculadas em escolas municipais centrais e periféricas. Trata-se de um estudo transversal realizado com 938 crianças de 7 a 10 anos no município de Viçosa, Minas Gerais, Brasil. Para avaliação antropométrica, foram aferidos peso, estatura e as dobras cutâneas tricipital e subescapular. O Índice de Massa Corporal (IMC) foi classificado de acordo com as recomendações da WHO (2007). A gordura corporal foi estimada pela fórmula proposta por Slaughter et al (1988) e classificada segundo McCarthy (2006). A análise estatística foi realizada no software SPSS versão 20.0, sendo considerado o nível de significância estatística de 5\%. Foi realizado o teste de Mann Whitney para comparar as medianas do IMC e da gordura corporal segundo a localização das escolas municipais (centrais ou periféricas). Este estudo foi aprovado pelo Comitê de Ética em Pesquisa com Seres Humanos da Universidade Federal de Viçosa. Foram encontradas altas prevalências de excesso de peso $243(25,9 \%)$ e de gordura corporal excessiva 284 (30,3\%). Crianças de escolas periféricas apresentam maior mediana de gordura corporal $(\mathrm{p}<0,05)$. Não foram encontradas diferenças estatísticas para as prevalências de excesso de peso entre crianças de escolas centrais e periféricas. As crianças matriculadas em escolas periféricas apresentam maior risco nutricional em relação ao percentual de gordura corporal quando comparadas àquelas de escolas centrais. Hipóteses sugeridas para estes achados é que as famílias de crianças residentes em bairros periféricos tendem a ter um menor poder aquisitivo, limitando, portanto, a participação das crianças em aulas de esportes, além da falta de espaços públicos adequados para essa prática nas localizações em que residem. A realização de ações em saúde voltadas para a prática da alimentação adequada e incentivo a atividade física devem ser adotadas na infância como forma de reduzir o impacto causado pelas doenças crônicas na população infantil.
\end{abstract}

Descritores: Obesidade; Estado nutricional; Crianças. 